\title{
Estancias divididas
}

\author{
Carlos López Degregori
}

1.

Cuando te regalan un reloj, te entregan "un pequeño infierno florido, una cadena de rosas, un calabozo de aire". Esta advertencia abre el "Preámbulo a las instrucciones para dar cuerda al reloj" de Julio Cortázar, uno de los textos más recordados de Historias de cronopios y de famas (1962). Mi primer reloj me lo obsequiaron mis padres el año de 1966 en mi cumpleaños. Era un pequeño Jowissa con caja de acero circular, sin aguja para los segundos y una correa de cuero negro que a mí me parecía una venda oscura. Yo vivía preocupado por su exactitud y lo comparaba con cualquier otro reloj que apareciera cerca. Preguntaba la hora. Observaba las muñecas ajenas. Lo regulaba si descubría un retraso y alimentaba su cuerda hasta el tope varias veces al día. A los pocos meses atrasaba unos minutos y al cumplir un año casi media hora. Dejé de usarlo y lo abandoné en un rincón para que muriera. No sé qué pasó con él: su destino forma parte de las zonas nebulosas de mi memoria.

El texto de Cortázar, con sus metáforas rítmicas y sucesivas que califican al reloj y al desdichado que lo posee, marca el ritmo del paso del tiempo. Es el sonido vivo del áncora y de las poleas y engranajes. Yo estoy en ese calabozo de aire y atisbo por el cristal circular. Cuelgo de las agujas como sucede en las películas mudas o en las ilustraciones horológicas que son parábolas. Es el tiempo que late y nos envuelve para conducirnos a la disolución. Me gustan los relojes. Tengo nueve de diferentes marcas y calidades que van intercalando mis días. Descansan en una caja que parece un pequeño ataúd con varios compartimientos. Siempre hay ocho en las almohadillas de terciopelo. El noveno se abraza a mi muñeca y aguarda el día del recambio para retornar a la caja.

No puedo vivir lejos de un reloj. No es que sea una persona obsesionada con la puntualidad, pero ellos marcan una cartografía necesaria en mis días. He construido un orden que aspira a ser inflexible, una dictadura en mi cotidianidad. Las agujas indican mis horas aproximadas para salir de casa y retornar; para leer, comer, escuchar música, ver televisión, defecar; para distribuir mis trabajos y actividades a lo largo de la semana y abrir las puertas del sueño cada noche. Desde hace un tiempo suelo despertarme en la noche y consulto el reloj: siempre es un instante que se aproxima a las tres. Luego lucho contra la vigilia y planifico mi día siguiente. El reloj es 
una reja horizontal y entre los barrotes se precipitan tensiones oscuras e imprecisas. $\mathrm{Al}$ fondo bullen el desorden y los deseos que pugnan por salir. $\mathrm{Y}$ lo consiguen. A veces son ensoñaciones. A veces transgresiones que deben transcurrir en la bruma y la invisibilidad. Y mis relojes siguen funcionando: son una coraza contra el miedo, un ritual protector que me aleja de las desestabilizaciones. Así reino en la quietud y me observo con "una expresión distante y a la vez curiosamente fija". Soy los ojos de alguien que se "ha inmovilizado en un momento de sueño y rehúsa dar el paso que lo devolvería a la vigilia". Estas palabras describen al sudamericano, ese imán en el que confluyen todas las fuerzas de "El otro cielo".

\section{2.}

Si tuviera que elegir un solo relato de Julio Cortázar me quedaría con "El otro cielo". El año 1972, conseguí en la librería Castro Soto la edición de Sudamericana que reunía sus cuatro primeros libros de cuentos. Mi ejemplar tiene unas tapas blancas de tela y el recuerdo de una cubierta azul que ya no existe. Fue uno de los primeros libros que adquirí después de días de ahorro y privaciones juveniles. Seguí la imposición del índice y la exigencia de leer un cuento cada día. No debía sobrepasarme ni permitir que mi curiosidad o avidez se desbordaran. Esa era la regla: un reloj de páginas blancas con letras como insectos - tal vez hormigas o abejas - que me cubrían. Cada relato ofrecía una intensificación y la promesa de una dádiva que aguardaba en la siguiente historia. Cuento ahora los relatos de mi libro y compruebo que son 39. "Allá al fondo está la muerte, pero no tenga miedo. Sujete el reloj con una mano, tome con dos dedos la llave de la cuerda, remóntela suavemente". Así sentencian las instrucciones de Cortázar. 39 días para llegar a la última página y cerrar las tapas blancas de tela. Con ese libro remonté un mecanismo que asesinaba la superficie. En la última jornada se hallaba "El otro cielo". ¿Lo entendí entonces? ¿Era un anuncio de mis días futuros? ¿Soy alguien inmovilizado en un momento de sueño que rehúsa o no puede dar el paso que lo devuelva a la vigilia?

$\mathrm{Al}$ igual que yo, el protagonista de este relato encarna el orden y sus rituales inflexibles. Vive bajo la tutela de su madre, trabaja en la Bolsa y visita por las tardes a Irma, su novia, quien aguarda, entre las conversaciones rutinarias, el matrimonio y los hijos futuros. Esa es la realidad insulsa y exacta en sus engranajes que lo encadena. Pero existe una dimensión secreta en su existencia que se manifiesta en la imantación de las galerías, esos pasajes de cristales oscurecidos que conectan mundos distintos. Como en cualquier relato fantástico, hay en esta historia un elemento anómalo y disociador: el protagonista tiene la facultad de alterar el espacio y el tiempo sin proponérselo. Ingresa en el Pasaje Güemes en la calle Florida y arriba con facilidad al cielo artificial de la 
Galerie Vivienne colmado de guirnaldas, figuras de yeso y lámparas de gas. Es un traslado de Buenos Aires a París, de 1945 a 1870. Un flujo bidireccional de disociación y unificación, de dobles y espejos, de días grises y noches artificiales que encarnan cielos a los que se asciende o se baja. Hay una escena en la que Josiane -la prostituta que es su pareja en París- sube las escaleras con una vela para llegar a su buhardilla. La atmósfera es frágil e inquietante y el miedo la envuelve. Ese tenue resplandor es la luz que ilumina ambas estancias y que debe mantenerse encendida. El relato es el itinerario de esa luz. El reconocimiento de su fulgor mayor y también el de su pérdida, porque es una peripecia construida desde la rememoración y la nostalgia.

"El otro cielo" es una historia de errancias, de paseos sin rumbo por Buenos Aires y especialmente París para alcanzar la "patria secreta" del narrador. Una primera lectura asocia ese desplazamiento con la huida y la compensación. París sería la transgresión de la ritualidad cotidiana, la patria prohibida con sus calles laberínticas y esquinas nebulosas, con sus cafés llenos de humo y mujeres galantes que parecen recortadas de un grabado o de alguna página de "El spleen de París" de Baudelaire. Allí vive Josiane con la promesa de su cuerpo, bebe ajenjo el sudamericano en una mesa solitaria y el asesino Laurent aterroriza a las prostitutas. Ese París nocturno y extemporáneo es el ámbito en el que el protagonista se despoja de su identidad y accede a un "cielo" de libertad y transgresiones. Pero el determinante "otro" implica que hay un cielo "uno" en alguna parte, tal vez muy cerca. Es el de la existencia ordenada, el de Irma y el trabajo disciplinado de cada día. La "patria verdadera" es así la posibilidad de ocupar simultáneamente esas dos estancias sin renunciar a ninguna, ambas son indispensables y cada una de ellas perfila su esencia en lo que le falta de la otra. La energía del relato es pendular y cada ciclo conecta dualidades: Buenos Aires y París, los dos siglos distintos, Irma y Josiane, el sudamericano y Laurent, el día iluminado del orden cotidiano y las grietas de la noche, la dádiva del sueño y la monotonía de la vigilia. Dos, siempre dos como las partes del relato marcadas por los epígrafes. Y el abrazo de estas dualidades.

\section{3.}

Esos ojos no te pertenecen. ¿De dónde los has tomado? Esta libre traducción del epígrafe, que proviene de Los cantos de Maldoror, fija el misterio de las galerías. ¿A qué ojos se refiere? ¿A los del narrador que se desplaza de Buenos Aires a París? ¿A los del sudamericano que es un personaje crucial a pesar de su reticencia? Hay una fuerza de la visión en "El otro cielo": una mirada implacable que fija la historia y las peripecias de los personajes. Una mirada que se mira mirar.

En el relato un voyeur bebe y observa. Cortázar se cuida de no revelar su identidad, pero llena las páginas de indicios. Se trata del sudamericano que es Isidore Ducasse 
y su reverso, el Conde de Lautréamont, quien se enmascara en Laurent. Las letras que faltan en su nombre revelan en sus vacíos el ser del que proviene. Isidore Lucien Ducasse, el poeta maldito o "raro", para emplear la calificación de Rubén Darío, nació el 4 de abril de 1846 en Montevideo. Se conocen pocos datos de su época uruguaya: era hijo de un funcionario del consulado general de Francia y transmitía, según algunas referencias de personas cercanas a la familia, la impresión de extrañeza. A los 14 años viajó a Francia y se educó como alumno interno en el liceo imperial de Tarbes. Los testimonios recogidos de su etapa estudiantil lo presentan flaco, encorvado, con la tez pálida y el cabello rebelde. Era un muchacho ensimismado, distante con el entorno y que poseía muchas aristas sombrías. Es elocuente una declaración de Eudoxie Ducasse -a propósito de un regreso del poeta en 1867 de Francia a su tierra natal- que revela una dualidad en su personalidad y un desborde incontrolable:

\begin{abstract}
mi sobrino siempre ha sido un hombre arrebatado, sí, muy arrebatado, un poco destructor, violento de forma intermitente, instintivo, apasionado y bastante loco. Sí, era todo eso, pero sabía recobrar su calma para volverse lógico después de haber aplacado su apetito sexual. Era siempre igual: cuando codiciaba a una mujer, estaba allí como un verdadero jaguar, elegante y peligroso.....
\end{abstract}

En 1865 se instaló en París para estudiar ciencias en la escuela politécnica y empezó a escribir febrilmente desde el círculo solitario que él mismo, por carácter o destino, se había trazado. Cambió varias veces de domicilio, pero se sabe que en 1870 habitó en la rue Vivienne y recorrió las mismas calles de "El otro cielo". Se cuenta que Ducasse escribía sobre un piano y acompañaba este proceso con acordes que tocaba intermitentemente. Un acorde supone la superposición de notas y así se despliega el relato con su duplicación de identidades, espacios y tiempos como ya lo he señalado. En 1977, Jacques Lefrère descubrió una fotografía suya que ahora se muestra en casi todas las ediciones de Los cantos... Aparece de pie con el brazo derecho apoyado en una media columna. Viste con discreción a pesar de las arrugas del traje y llaman la atención las manos desproporcionadamente grandes - tal vez sea un efecto de la perspectiva del retrato- que podrían golpear, tocar el piano o estrangular con facilidad. La mirada melancólica se dirige a un punto que lo perturba y es tentador identificar esos ojos con los del sudamericano.

"No me gusta esa manera que tiene de mirarnos", dice Josiane. Y añade luego: "no te mira, la verdad es que te clava los ojos pero no te mira". El no mirar a los otros implica que son apenas nebulosos sucedáneos o que es el observador el que los crea. Sutilmente el relato insinúa que ese París presentado como un telón en la noche y la niebla es la proyección del muchacho sudamericano para escenificar el misterio de las correspondencias. Es reveladora una acotación del narrador:

1 Testimonio de Eudoxie Ducasse a Guillot-Muñoz. Citado por Mauro Armiño, en Los cantos de Maldoror (2016, p. 18). 
Lo vi pagar su ajenjo echando una moneda en el platillo de peltre mientras dejaba resbalar sobre nosotros -y era como si cesáramos de estar allí por un segundo interminable- una expresión distante y a la vez curiosamente fija, la cara de alguien que se ha inmovilizado en un momento de sueño y rehúsa dar el paso que lo devolverá a la vigilia. (Cortázar, 1970, pp. 557-558)

Es el instante de la inmovilidad en el que los personajes se desvanecen en ese punto entre el sueño y la vigilia, "cesan de estar". Lo material se desmaterializa. La ficción se curva sobre sí misma. Todo tiene la consistencia del sueño en ese vértigo de las correspondencias y oposiciones: Irma y Josiane, el empleado ejemplar y el transgresor que recorre la noche, el Río de la Plata y París, el sudamericano y Laurent. Es como el poema de Baudelaire en el que las dualidades se movilizan en "ecos prolongados que de lejos se confunden en una tenebrosa y profunda unidad". Creo que este verso de "Correspondencias" esclarece la dinámica del relato que es siempre oscuro - no se menciona ningún color en la escenificación de esta historia, solo sombras alargadas en blanco y negro- y de honduras irreconocibles:

Después de todo una expresión como esa, aunque el muchacho fuese casi un adolescente y uviera rasgos muy hermosos, podía llevar como de la mano a la pesadilla recurrente de Laurent. No perdí tiempo en proponérselo a Josiane. - ¿Laurent? ¡Estás loco! Pero si Laurent es... (Cortázar, 1970, p. 558)

Los puntos suspensivos eliden la revelación definitiva y a la vez conectan las estancias o cierran las guirnaldas que adornan las calles parisinas. Si Laurent es Lautréamont, el narrador que recorre las calles parisinas es también el sudamericano, la proyección de Ducasse para verse a sí mismo en su lado más humano. La clausura del relato teje estas correspondencias:

Nunca he querido admitir que la guirnalda estuviera definitivamente cerrada y que no
volvería a encontrarme con Josiane en los pasajes o los bulevares. Algunos días me da por
pensar en el sudamericano, y en esa rumia desganada llego a inventar como un consuelo,
como si él nos hubiera matado a Laurent y a mí con su propia muerte; razonablemente me digo
que no, que exagero, que cualquier día volveré a entrar en el barrio de las galerías y encon-
traré a Josiane sorprendida por mi larga ausencia. Y entre una cosa y otra me quedo en casa
tomando mate, escuchando a Irma que espera para diciembre, y me pregunto sin demasiado
entusiasmo, si cuando lleguen las elecciones votaré por Perón o Tamborini, si votaré en blanco
o sencillamente me quedaré en casa tomando mate y mirando a Irma y a las plantas del patio.
(Cortázar, 1970, p. 576)

Este es el cierre del relato que muestra sutilmente la muerte y la pérdida del sueño parisino. Con su partida, el sudamericano se ha llevado el acceso al "otro cielo". El primer signo ya se ha manifestado: es el instante previo a la ejecución en la guillotina de Laurent en el que el sudamericano se extravía en la "contemplación imperfecta de la máquina". Una imperfección supone un quiebre, un desajuste que se encamina a un final. Se desvanecerán el Passage des Panoramas y la Galerie Vivienne con una Josiane cada vez más ausente. Y va triunfando el olor a aserrín y lejía del pasaje Güemes, las obligaciones de las ruedas de bolsa, la insistencia de Irma que es calificada como una 
"novia araña". Isidore Ducasse murió de fiebres malignas en la habitación de su hotel al igual que el sudamericano. En el relato de Cortázar hay "un miserable cirio ardiendo" al lado de su cadáver y la consola atestada de libros y papeles. El narrador contempla así la disolución de uno de sus "cielos". No puede haber en esta historia otra conclusión: hay que mirar ahora a Irma y a las flores del patio. Los ojos del sudamericano ya no existen, pero con su muerte los ha legado a la cotidianeidad del narrador que se mira a sí mismo. El empleado rioplatense ha extirpado de sí al sudamericano para refugiarse en su coraza de seguridad. La historia despliega una renuncia: en alguno de los cielos hay que afincarse y dejar que el tiempo transcurra.

\section{4.}

Recorro otras estancias divididas y descubro a alguien que se distancia también para mirar. Es Wakefield, el personaje desconcertante de Nathaniel Hawthorne. El extrañamiento es su intención, la búsqueda de una lejanía íntima, cercana, al lado de su casa.

El narrador recoge una historia aparentemente trivial que leyó alguna vez en un diario londinense. Allí encontró a Wakefield, un ser casi sin contornos que sufría una "especie de aletargamiento que mantenía su corazón en reposo". Era un "intelectual, pero no de manera activa", un ser encadenado a la abulia y la cotidianidad. Una tarde le anuncia a su mujer que se ausentará algunos días. Ha decidido alejarse un tiempo para espiar su ausencia y acceder tal vez a su centro de incomprensibilidad. Se instala en una habitación cerca de su casa y contempla su acción - trivial o grandiosa- semanas, meses, años. Va cambiando. Su figura se encorva y adelgaza, nadie lo reconoce, ni siquiera su mujer con quien se cruza en un momento de la historia. Son veinte años y una noche de lluvia llega a la puerta de su casa. Siente el fuego tibio de la chimenea en el interior. Entonces atraviesa el umbral y nunca sabemos qué pasará. El relato queda en suspenso. ¿Qué objetivo orienta la huida de Wakefield? Creo que es el esfuerzo de negar su insignificancia, el no-valor que es su insignia ante los otros. Es nadie. Para él no hay un "otro cielo", ha fabricado para su desaparición una "pequeña esfera de criaturas en la que él era el objeto central". La visión es también definitiva en este relato:

\footnotetext{
Pero, ¡centrémonos ahora en una escena! En medio de la multitud de una calle cualquiera de Londres, distinguimos a un hombre que ya se está haciendo mayor y que posee pocos rasgos que llamen la atención de distraídos observadores; y, sin embargo, para aquellos que tengan la capacidad de verlo, porta en su aspecto la impronta de un destino poco común. Esta delgado; su frente pequeña y estrecha está profundamente arrugada; algunas veces sus pequeños y apagados ojos vagan temerosos a su alrededor, aunque más frecuentemente parecen mirar hacia adentro. (Hawthorne, 2011, p. 41)
}

Se trata de una mirada especular, hacia adentro. Solo mira el no-cielo de su cuerpo, de su casa, de su identidad. Es lo único que posee y por eso vuelve a ella. Hay una 
oposición en las miradas de estos dos relatos. En el primero el ojo se abre a la creación de otros seres y cuerpos en el ámbito del sueño y la ficción, allí está la "verdadera patria". En Wakefield, en cambio, el ojo se repliega hasta extraviarse en su dolorosa intimidad. No existe "otro cielo", solo la repetición fija del espacio cotidiano del que es imposible alejarse. Dos estancias que puedo representar gráficamente:

El CIELO UNO



EL NARRADOR

EL NO CIELO

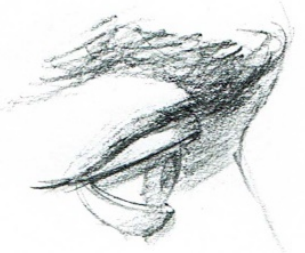

Wakefield
EL OTRO CIELO



EL SUDAMERICANO

EL NO CIELO



Wakefield

Estancia es estar: mirar y mirarse. Isidore Ducasse viajó a Francia para presentarse a la Escuela Politécnica. Las matemáticas lo apaciguaban o tal vez le proporcionaban un escudo para enfrentar la lava hirviente de su escritura. “¡Oh matemáticas severas! No os he olvidado desde que vuestras sabias lecciones, más dulces que la miel, se filtraron en mi corazón, como onda refrescante". Esas son las estancias divididas: el orden y la entropía que huye a los abismos.

\section{5.}

Construimos relojes y hierros para que nos ciñan. Nos aventuramos por pasajes desconocidos que no sabemos a dónde nos conducen. Inventamos vidas, presencias, gestos, huidas. Nunca es suficiente, necesitamos un tumulto de existencias iguales y distintas, sin matemáticas severas y sin que nadie pueda reconocer la verdadera. Levanto la tapa de la caja que guarda mis relojes y elijo el que llevaré este día. Siento que se juega algo 
desconocido. Cada mañana me cuesta más decidir. Renuncio al azar y su árbol de elecciones, a sus meandros y caídas. Mis relojes señalan las horas de varios cielos distintos y en alguno debo al fin quedarme a esperar que el tiempo se detenga.

\section{REFERENCIAS}

Baudelaire, Ch. (2018 [1869]). El Spleen de París, trad. de Margarita Michelena; 2. ${ }^{\text {e ed. }}$ México: Fondo de Cultura Económica.

Conde de Lautréamont (Isidore Lucien Ducasse) (2016 [1869]). Los cantos de Maldoror. Madrid: Valdemar.

Cortázar, J. (1970 [1962]). Historias de Cronopios y de Famas. Buenos Aires: Editorial Sudamericana.

Cortázar, J. (1970). Relatos. Buenos Aires: Editorial Sudamericana.

Hawthorne, N. (2011). Wakefield. Madrid: Nórdica Libros. 